\title{
Game Theory Analysis about the Red Packet Money
}

\author{
Rui Bai \\ School of Humanities \\ Southwestern University of Finance and Economics \\ SWUFE \\ Chengdu, China
}

\author{
Weiyu Pan* \\ School of Humanities \\ Southwestern University of Finance and Economics \\ SWUFE \\ Chengdu, China
}

\author{
Chao Li \\ School of Economics \\ Southwestern University of Finance and Economics \\ SWUFE \\ Chengdu, China
}

\begin{abstract}
The red packet money is a topic of great concern in recent years. It originated in the late Ming Dynasty and early Qing Dynasty and became extravagant in the late Qing dynasty and the Republic of China. It is hard to say that this kind of money at present is an authentic traditional custom. However, it is a rising part in every person's spending. This paper applies simple game analysis, finding that the emergence and development of the red packet money obviously have the characteristics of so-called the Prisoners' Dilemma. It is difficult for rational people in the market economy to make decisions to set a reasonable standard through their own adjustments. The prevalence of red packet is usually accompanied by extravagant rituals that are not commensurate with the actual economic level. In order to solve this problem, we need corresponding government guidance.
\end{abstract}

Keywords - Red packet; Game theory; Prisoners' dilemma

\section{INTRODUCTION}

In recent years, consumption in China has remained sluggish. However, in stark contrast, it seems like that people are getting more and more generous on red packet money. Why are people so generous in terms of contacts? What is the reason that families, especially those with low income level, are still unwilling to reduce expenses on red packet money despite the fact that they cannot make ends meet? To answer these questions apparently has very important theoretical and practical significance ${ }^{[1]}$.

Compared with the gift money given to children on lunar New Year, the red packet money on wedding have a much shorter history, emerging in the late Ming Dynasty and early Qing Dynasty, becoming extravagant in the late Qing Dynasty and the Republic of China, and prevailing in society nowadays , it can hardly be regarded as authentic traditional customs. However, red packet money is a rising part in every person's spending, and it can be caused by the holding of wedding or funeral, moving to a house, being admitted by college, and so forth. Where there is a reason, there is red packet money. Coupled with the auspicious number which Chinese people believe in, $600,800,1000$ or even 6,000 RMB of red packet money came into being ${ }^{[1]}$. It is naturally not possible to hold

Fund Project: Sichuan Provincial Social Science "13th Five-Year" Fund Proiect (SC16C049). simple rituals given the condition of receiving a number of red packet money. For example, hundreds of tables are not uncommon for wedding ceremonies.. According to statistics, wedding expenses in China account for about $2 \%$ of the total $\mathrm{GDP}^{[2]}$. A huge number of various kinds of red packet money has gradually become an increasingly heavy burden on the people, but it also makes people dare not express anger. With regard to how this kind of money has been generated in recent years and why the amounts have risen in value and what influence it has on people, this article will give a brief explanation on this matter with a static game between the two parties.

\section{ACCEPTING OF RED PACKET}

Assuming that both $\mathrm{A}$ and $\mathrm{B}$ decided to marry in the same year and all sent invitations to each other. Each of them would have to decide whether to charge each other an amount of red packet money in cash which is $m$ in amount, and the opportunity cost for raising that portion of cash (for example, to divest investment projects, to give up some of the consumer budget, etc.) which is $i$ in amount. Under the premise of rational consensus, the game matrix can be simply expressed as Table 1 shows:

TABLE I. GAME MATRIX OF ACCEPTING RED PACKET

\begin{tabular}{|c|c|c|c|}
\hline \multicolumn{2}{|c|}{} & \multicolumn{2}{c|}{ B } \\
\cline { 3 - 4 } \multicolumn{2}{|c|}{} & Accept & Not Accept \\
\hline \multirow{3}{*}{ A } & Accept & $-i,-i$ & $m,-m-i$ \\
\cline { 2 - 4 } & Not accept & $-m-i, m$ & 0,0 \\
\hline
\end{tabular}

In fact (Accept, Accept) is the Nash equilibrium formed by the dominant strategy of $\mathrm{A}$ and $\mathrm{B}$, thus forming a game pattern similar to the Prisoners' Dilemma. As the host of the wedding, both $\mathrm{A}$ and $\mathrm{B}$ will choose to receive red packet money, and ultimately both parties cannot benefit from the unilateral deviation. Compared with the result of the game (Not Accept, Not Accept), the losses of both parties are the costs for the purpose of raising the red packet money. 
Similar to the Prisoners' Dilemma, when both individuals decide not to accept red packet money, the outcome of the game is more favorable, but each side is motivated to unilaterally accept. Fearful of this threat, both parties will choose to receive their share of red packet money.

In short, the main reason is that red packet appears to be profitable for every person respectively. From a personal point of view, any refusal to accept a red envelope will directly result in a large loss of income, but when everyone in society tries to profit from such behavior, the prevalence of red packet money is nothing more than "a transfer from left hand to right hand". In other words, people will lose some of the opportunity costs because of such behavior, which is the only result of frustration. This awkward situation is also very difficult to solve simply through enlightenment because education actually enables people to grasp the laws governing the operation of the present society more accurately. With people are served as an "exquisite egoist", there exists the maximum conformity to current social rules like the pursuit for profits and "person in society". This may mean that the government's propaganda, intervention and regulation have swift and obvious effects on this issue. Although this probably violates the right of people to choose freely, such choices do not, after all, result in good conditions for themselves.

\section{GIVING OF RED PACKET}

Then consider a more complicated situation. Assuming that the specific amount of red packet money is not decided by the wedding organizers, but made decisions by participants. That is, A and B each choose a high amount $m_{h}$ or a low amount $m_{l}$, and the corresponding opportunity cost of money-raising is $i_{h}$ and $i_{l}$ respectively. But for any part, if his opponent gives higher amount of money than himself, there will be a loss F (for example, the so-called "face" effects), and both parties consider this loss is so tremendous that it is greater than the differences between high and low red packet money plus the cost for raising that kind of money, namely (1):

$$
F>\left(i_{h}-i_{l}\right)+\left(m_{h}-m_{l}\right)
$$

So under the rational consensus, the game matrix can be expressed similarly in Table 2:

TABLE II. GAME MATRIX OF GIVING RED PACKET

\begin{tabular}{|c|c|c|c|}
\hline \multicolumn{2}{|c|}{} & \multicolumn{2}{|c|}{ B } \\
\cline { 2 - 4 } \multicolumn{2}{|c|}{} & High Amount & Low amount \\
\hline \multirow{4}{*}{ A } & $\begin{array}{c}\text { High } \\
\text { Amount }\end{array}$ & $-i_{h},-i_{h}$ & $-\left(m_{h}-m_{l}\right)-i_{h}$ \\
& & &,$\left(\mathrm{~m}_{\mathrm{h}}-\mathrm{m}_{l}\right)-F-i_{l}$ \\
& Low & $\left(m_{h}-m_{l}\right)-F-i_{l}$, & \\
& amount & $-\left(m_{h}-m_{l}\right)-i_{h}$ & $-i_{l},-i_{l}$ \\
\hline
\end{tabular}

There are two available Nash equilibriums (High Amount, High Amount) and (Low Amount, Low Amount), while the latter have a higher overall welfare level. It is difficult to draw a certain conclusion based on classical game theory. But if we further assume (2):

$$
F>\left(i_{h}-i_{l}\right)+2\left(m_{h}-m_{l}\right)
$$

In other words, compared with the optimal game outcome (Low Amount, Low Amount), the two parties both believe that the utility loss caused by the opponent's giving more red packet money is so great that they would rather take the risk of giving more than bear the loss of giving less. Table 3 illustrates what will happen under above conditions. Then the result is rather simple, that is, both individuals will try to give a high amount of money. But both of them may still reach a better Nash equilibrium of giving less if there are additional signals or interventions.

TABLE III. OUTCOMES IN DIFFERENT SITUATIONS

\begin{tabular}{|c|c|c|c|}
\hline & $\begin{array}{c}\text { The Best } \\
\text { Result }\end{array}$ & $\begin{array}{c}\text { Higher Than } \\
\text { Opponent }\end{array}$ & $\begin{array}{c}\text { Lower than } \\
\text { Opponent }\end{array}$ \\
\hline Outcome & $-i_{l}$ & $-\left(m_{h}-m_{l}\right)-i_{h}$ & $\left(m_{h}-m_{l}\right)-i_{h}-F-i_{l}$ \\
\hline Loss & & $\left(i_{h}-i_{l}\right)+\left(m_{h}-m_{l}\right)$ & F- $\left(m_{h}-m_{l}\right)$ \\
\hline
\end{tabular}

The welfare implications of spending in order to "keep up with the Joneses" are potentially large ${ }^{[4]}$, and everyone will give as much money as possible. Although this is a universal fate for everyone in the community, it becomes a heavy burden on poor families or people.

\section{CONCLUSION}

Red packet money represents a blessing to new couples, but it can never replace feelings after all no matter how much money is given, let alone decide whether people are close. There is a common view that red packet money should not be the measure of relationships. Over the years, Chinese government has repeatedly advocated that marriage and funeral rituals should be frugal and extravagance is forbidden. In reality, however, the wedding ceremony is getting bigger and bigger with the red packet money is becoming more and more, which causes the original communications and emotions among people are turning alienated.

With the rapid economic development in China, it can be expected that the expenditure of red packet will increase at the same pace as per capita disposable income, or it will even be that the rate of increase in red packet money is far greater than the rate of increase in income. At present the truth is, from the perspective of the whole country, that the expenditure on human affairs in China does show the characteristics of high proportion of total income and rapid growth. For example, the data $^{[5]}$ from China Household Finance Survey (CHFS) at Southwestern University of Finance and Economics in 2011 show that on the whole the expenses Chinese families spent on holidays and weddings and funerals account for an average of $7.9 \%$ of the total household net income; furthermore, the rate will rise to $11.4 \%$ considering only rural households; while the rate will increase sharply to $45.1 \%$ if only families with income below the first quartile of all household income are considered. As another example, according to the survey data ${ }^{[6]}$ of Chinese Family Panel Studies (CFPS) in 2010 and 2014, the change of the total expenditure on red packet money in terms of family units rose from 2286.2 RMB in 2010 to 3833.6 RMB in 2014 , increasing about $67.0 \%$. As for the proportion which average household expenditure on red packet money accounts for of average household net income, expenditure relative to red packet rose from $6.9 \%$ in 2010 to $8.2 \%$ in 2014, an increase of about $18.6 \%$ as shown in Table 4. 
TABLE IV. OVERALL CHANGE OF RED PACKET MONEY

\begin{tabular}{|c|c|c|}
\hline Year & 2010 & 2014 \\
\hline Expenditure & 2286.2 & 3833.6 \\
\hline Income & 33277.7 & 47051.0 \\
\hline Proportion & $6.9 \%$ & $8.2 \%$ \\
\hline
\end{tabular}

Note: "Expenditure" stands for average household expenditure on red packet money; "Income" stands for average household net income; "Proportion" stands for average household expenditure on red packet money accounts for the proportion of average household net income.

It can be seen that under the assumption of a rationality, the custom of the red packet money can in fact lead to a decline in welfares of everyone, and it does not only spread very fast, but also increases greatly in the amount. As a kind of folk custom or a similarly social network ${ }^{[7]}$, it is very difficult to regulate directly with the administrative order, nor can it be expected to improve itself within a short period of time. Based on the analysis above, the promotion of thrifty gift custom or the decision of amount of money made by hosts rather than participants should be more feasible at this stage.

\section{REFERENCES}

[1] Hang Bin, Cao Jian-mei. Research on Rural Households' Gift Spending in China: Based on Double Perspectives of Both Income Inequality and Social Status [J]. Statistics \& Information Forum, 2017, 32(5): 116-122.(In Chinese)

[2] Data from the Sohu network[OL], http://www.sohu.com/a/100729060 443188. 2016, 07. 02.

[3] Data from the Sohu network[OL],

http://www.sohu.com/a/197906308_658403. 2017,10.13.

[4] Brown P H, Bulte E, Zhang X. Positional spending and status seeking in rural China[J]. Journal of Development Economics, 2011, 96(1): 139-149.

[5] Li Gan, Zhichao Yin, Nan Jia, Shu Xu, Shuang Ma, 2013, Data you need to know about China, Springer.

[6] The data are from China Family Panel Studies (CFPS)[DB], funded by 985 Program of Peking University and carried out by the Institute of Social Science Survey of Peking University.

[7] Chen X. Gift-giving and network structure in rural China: utilizing long-term spontaneous gift records[J]. PloS one, 2014, 9(8): e102104. 